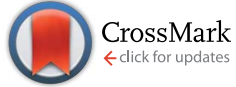

Cite this: Chem. Sci., 2017, 8, 689

Received 27th July 2016

Accepted 25th August 2016

DOI: $10.1039 / \mathrm{c} 6 \mathrm{sc} 03335 \mathrm{k}$

www.rsc.org/chemicalscience

\section{Bimetallic nanosized solids with acid and redox properties for catalytic activation of $\mathrm{C}-\mathrm{C}$ and $\mathrm{C}-\mathrm{H}$ bonds $\dagger$}

\author{
Jose R. Cabrero-Antonino, ${ }^{a}$ María Tejeda-Serrano, ${ }^{a}$ Manuel Quesada, ${ }^{a}$ Jose A. Vidal- \\ Moya, ${ }^{a}$ Antonio Leyva-Pérez ${ }^{\star a}$ and Avelino Corma*ab \\ A new approach is presented to form self-supported bimetallic nanosized solids with acid and redox \\ catalytic properties. They are water-, air- and $\mathrm{H}_{2}$-stable, and are able to activate demanding $\mathrm{C}-\mathrm{C}$ and \\ $\mathrm{C}-\mathrm{H}$ reactions. A detailed mechanistic study on the formation of the $\mathrm{Ag}-\mathrm{Fe}$ bimetallic system shows that \\ a rapid redox-coupled sequence between $\mathrm{Ag}^{+}, \mathrm{O}_{2}$ (air) and $\mathrm{Fe}^{2+}$ occurs, giving monodisperse $\mathrm{Ag}$ \\ nanoparticles supported by $\mathrm{O}$-bridged diatomic $\mathrm{Fe}^{3+}$ triflimides. The system can be expanded to $\mathrm{Ag}$ \\ nanoparticles embedded within a matrix of $\mathrm{Cu}^{2+}, \mathrm{Bi}^{3+}$ and $\mathrm{Yb}^{3+}$ triflimide.
}

\section{Introduction}

Metal triflimides $\mathrm{M}^{n+} \mathrm{Tf}_{n}\left[\mathrm{M}\right.$ : metal cation, $\left.\mathrm{Tf:}{ }^{-} \mathrm{N}\left(\mathrm{SO}_{2} \mathrm{CF}_{3}\right)_{2}\right]$ are strong Lewis acids due to the high delocalization of the negative charge in the triflimide anion, which confers high mobility to associated cations and protons. Contrary to other soft acids with highly delocalized anions (i.e. tetrafluoroborates and hexaflurometalates), triflimide salts are relatively stable and safeto-handle ${ }^{1}$ and, for instance, LiNTf $_{2}$ is commercially employed as an electrolyte in batteries. These properties make triflimide salts powerful Lewis acid catalysts to activate $\mathrm{C}-\mathrm{C}$ bonds and, if the redox properties of the metal cation are tuned with ligands, also very active catalysts to oxidize reluctant $\mathrm{C}-\mathrm{H}$ bonds. ${ }^{2}$ However, both acid/redox functions are typically mutually exclusive and their concomitant use in a single reaction is hampered. Besides that, triflimide salts are expensive and difficult to recover when in solution, which limits their use basically to a laboratory scale. Thus, it is clear that the synthesis of a recoverable solid triflimide catalyst, insoluble in common solvents, and with its acid/redox sites operative at the same time, would solve those problems. However, to our knowledge, no solid triflimide has been reported yet. ${ }^{3,4}$ Here we present a new preparation concept that allows the formation of a family of triflimide solids with very strong acidity and readily available redox metal sites. The material consists of metal $\left(\mathrm{Fe}^{3+}, \mathrm{Cu}^{2+}\right.$,

${ }^{a}$ Instituto de Tecnología Química, Universitat Politècnica de València-Consejo Superior de Investigaciones Científicas, Avda. de los Naranjos s/n, 46022, Valencia, Spain. E-mail: acorma@itq.upv.es; anleyva@itq.upv.es; Fax: +34 9638 77809; Tel: +34 963877800

${ }^{b}$ King Fahd University of Petroleum and Minerals, P. O. Box 989, Dhahran 31261, Saudi Arabia

$\dagger$ Electronic supplementary information (ESI) available: General procedures, additional figures and tables, compound characterization and NMR copies. See DOI: $10.1039 / \mathrm{c} 6 \mathrm{sc} 03335 \mathrm{k}$
$\mathrm{Yb}^{3+}$ or $\left.\mathrm{Bi}^{3+}\right) \mu$-oxide triflimides on $\mathrm{Ag}$ nanoparticles (Ag NPs) concomitantly formed under ambient conditions, after adding thiophenol to a solution of the corresponding metal triflimide and $\mathrm{Ag}^{+}$. The mechanism follows a simple redox-coupled sequence to furnish self-supported solids that behave as efficient acid, redox and acid/redox heterogeneous catalysts for different $\mathrm{C}-\mathrm{H}$ and $\mathrm{C}-\mathrm{C}$ activation reactions.

\section{Results and discussion}

\subsection{Synthesis, characterization and structure of the solid} $\mathrm{Fe}_{2} \mathrm{O}\left(\mathrm{NTf}_{2}\right)_{5} @ A g N P s$

Fig. 1 shows the preparation of the solid material. The procedure consists of mixing $\mathrm{Fe}^{3+}$ triflimide $\left[\mathrm{Fe}\left(\mathrm{NTf}_{2}\right)_{3}\right]$ with $\mathrm{Ag}$ triflimide ( $\mathrm{AgNTf}_{2}, 0.1-1.0$ equivalent) in 1,4-dioxane at room temperature, and then adding one equivalent of thiophenol ( $\mathrm{PhSH})$ at once. A soft yellow solid precipitates in up to $90 \%$ yield in 2 gram scale for $\mathrm{Ag}:$ Fe molar ratio $=0.5$.

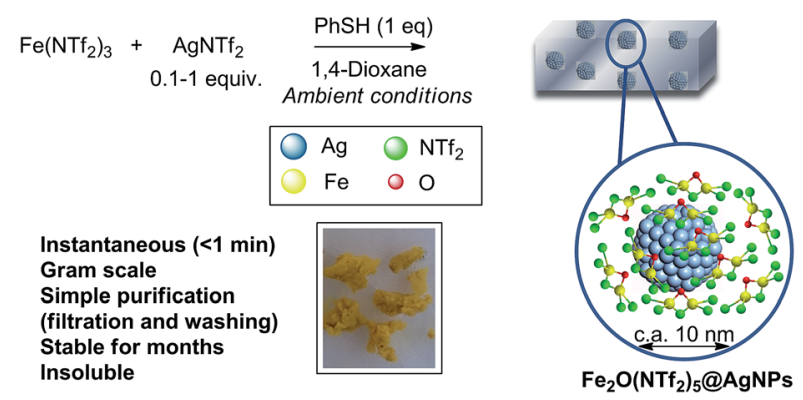

Fig. 1 Synthesis of $\mathrm{Fe}_{2} \mathrm{O}\left(\mathrm{NTf}_{2}\right)_{5} @ \mathrm{aAgNPs}$. Reaction conditions: Fe $\left(\mathrm{NTf}_{2}\right)_{3}$ (6.16 mmol), AgNTf 2 (0.1-1.0 equivalent), thiophenol (6.16 $\mathrm{mmol}$ ), 1,4-dioxane ( $80 \mathrm{~mL}$ ), room temperature, $<1 \mathrm{~min}$ to $1 \mathrm{~h}, 28-90 \%$ yield. See details in ESI. $\uparrow$ A photograph of the yellow solid and a model (not scaled) are also provided. 
Analysis using inductively coupled plasma-atomic emission spectroscopy (ICP-AES) gives $5.8 \mathrm{wt} \%$ of Fe and $6.2 \mathrm{wt} \%$ of Ag for the solid prepared with an $\mathrm{Ag}: \mathrm{Fe}$ molar ratio $=0.5$, which accounts for the amounts of $\mathrm{Fe}$ and $\mathrm{Ag}$ atoms initially added. Elemental analysis (CHNS) of the solid gives a sulfur-to-nitrogen ratio of $2: 1$, that corresponds exactly to triflimide anions, and that in principle discards the presence of thiophenol in the structure. Analysis of the organic molecules present in the solid after dissolution in $\mathrm{HNTf}_{2}$, extraction with diethyl ether and quantification using gas chromatography-mass spectrometry (GC-MS) with $n$-dodecane as an external standard, confirms the lack of thiols and shows the presence of $\sim 15 \mathrm{wt} \%$ of 1,4dioxane. Thermogravimetric (TG) analysis (Fig. S1 in ESI $\uparrow$ ) confirms the amount of 1,4-dioxane present (16 wt\%, loss at $\sim 100{ }^{\circ} \mathrm{C}$ ) and also shows that the material contains $4 \mathrm{wt} \%$ of water and two types of triflimide anions, that desorb at $\sim 20{ }^{\circ} \mathrm{C}$ $(10 \mathrm{wt} \%)$ and $300^{\circ} \mathrm{C}(47 \mathrm{wt} \%)$. With all these data in hand, we can calculate the initial formula $\mathrm{Ag}_{0.5} \mathrm{Fe}\left(\mathrm{NTf}_{2}\right)_{2.5} \cdot$ (dioxane $)_{2-3} \cdot \mathrm{H}_{2} \mathrm{O}_{1-2}$ for the solid material.

Fig. 2 shows transmission electron microscopy (TEM) photographs of the material (Ag loading $5.1 \mathrm{wt} \%, 0.5$ equivalents of starting Ag) and well-dispersed, crystalline Ag NPs can be seen. Electron-dispersive X-ray (EDX) analysis indicates that the analyzed area of the NP is mainly Ag (98.5\%), and mapping of $\mathrm{Ag}$ and $\mathrm{Fe}$ atoms in the whole micrograph shows that, while all $\mathrm{Ag}$ atoms are concentrated in the NP, Fe atoms are dispersed throughout the micrograph. On average, the material presents the expected molecular Ag: Fe mol ratio (0.5) and the photographs suggest that the Ag NPs are somehow embedded within a matrix of Fe.

The classical analytical test for $\mathrm{Fe}^{2+}$ with ICl does not give any trace of $\mathrm{Fe}^{2+}$ in the solid after dissolution with $\mathrm{HNTf}_{2}$. In contrast, the analytical test with $\mathrm{SnCl}_{2}$ gave $\mathrm{Fe}^{3+}$ as the only iron species present in the solid. The diffuse reflectance ultraviolet-visible (RD-UV vis) spectrum of the solid shown in Fig. 3 (top-left) confirms the absence of d-d transition bands for low spin $\mathrm{Fe}^{2+}$ complexes, that should appear at around
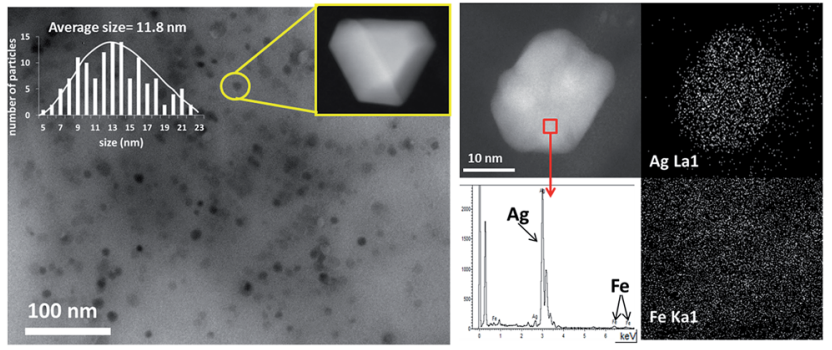

Fig. 2 Left: a transmission electron microscopy (TEM) photograph of the $\mathrm{Fe}_{2} \mathrm{O}\left(\mathrm{NTf}_{2}\right)_{5} @ \mathrm{Ag} \mathrm{ANPs}$ solid $(\mathrm{Ag}$ : Fe mol ratio $=0.5)$ where welldispersed Ag nanoparticles ( $\sim 12 \mathrm{~nm}$ average size) can be appreciated, with the corresponding histogram for at least 5 different photos and 150 particles. The inset shows a scanning transmission electron microscopy-dark field (STEM-DF) photograph of a well-faceted Ag NP. Right: scanning transmission electron microscopy-dark field (STEMDF) micrograph of an Ag NP with the corresponding electrondispersive $X$-ray (EDX) analysis of the squared area and the mapping for Ag (top) and Fe (bottom).
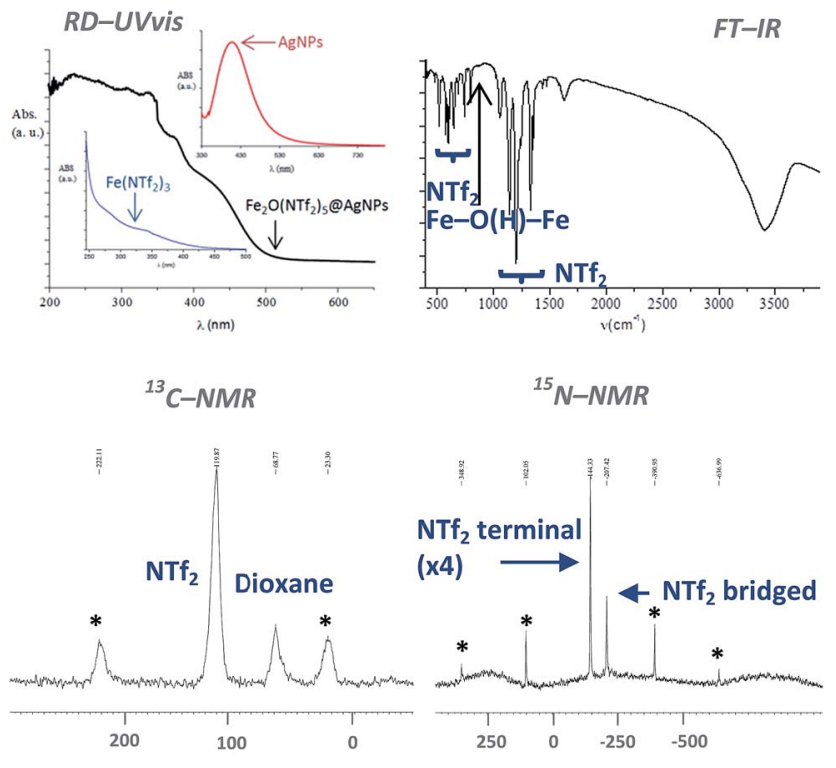

ESI-MS

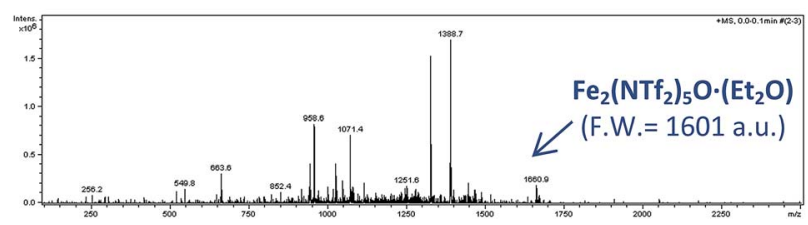

Fig. 3 Top: Fourier transform-infrared (FT-IR) and diffuse reflectance ultraviolet-visible (RD-UV vis) spectra of the $\mathrm{Fe}_{2} \mathrm{O}\left(\mathrm{NTf}_{2}\right)_{5} @ \mathrm{AgNPs}$ solid. For the sake of comparison, the UV-vis spectra of Fe $\left(\mathrm{NTf}_{2}\right)_{3}$ and $10 \mathrm{~nm}$ Ag nanoparticles in solution are also shown. Middle: ${ }^{13} \mathrm{C}$ and ${ }^{15} \mathrm{~N}$ nuclear magnetic resonance-magic angle spinning (NMR-MAS) spectra of the ${ }^{15} \mathrm{~N}$ isotopically-labelled yellow solid (* = rotational peaks). Bottom: electrospray ionization mass spectrum (ESI-MS) of the solid extracted with diethyl ether.

$600 \mathrm{~nm}$. These results indicate that $\mathrm{Fe}^{3+}$ is the main iron species present in the solid, with less than $0.1-0.01 \%$ of $\mathrm{Fe}^{2+}$. Notice that the RD-UV vis spectrum fits well with the sum of the individual absorption spectra of independently-prepared $\mathrm{Fe}\left(\mathrm{NTf}_{2}\right)_{3}$ and AgNPs (see ESI $\dagger$ ).

Fig. 3 (top-right) shows the Fourier transform-infrared (FTIR) spectrum of the material with the presence of two different triflimide peaks (see Table S1 in ESI $\dagger$ for a complete list of bands and discussion), in accordance with the TG analysis. The triflimide anions are coordinated to Fe cations either through the oxygen or nitrogen atoms of the triflimide groups. ${ }^{5}$ The IR spectrum also reveals that a $\mu$-hydroxo or $\mu$-oxo bridge between two Fe atoms is present. ${ }^{6}$ These results indicate that the solid is formed by oxo-bridged $\mathrm{Fe}_{2} \mathrm{O}\left(\mathrm{NTf}_{2}\right)_{5}$ species.

Fig. 3 (middle) shows the ${ }^{13} \mathrm{C}$ nuclear magnetic resonancemagic angle spinning (NMR-MAS) spectrum of the solid, with the expected peaks for 1,4-dioxane ( $\sim 69 \mathrm{ppm})$ and triflimide $(\sim 120 \mathrm{ppm})$. Since no differentiation by ${ }^{13} \mathrm{C}$ NMR can be expected for different triflimides, we prepared a sample of isotopically-labelled ${ }^{15} \mathrm{~N}$-solid, i.e. $\mathrm{Fe}_{2} \mathrm{O}\left({ }^{15} \mathrm{~N}-\mathrm{Tf}_{2}\right)_{5} @ A g N P s$, by using $\mathrm{Fe}\left({ }^{15} \mathrm{NTf}_{2}\right)_{3}$ and $\mathrm{Ag}^{15} \mathrm{NTf}_{2}$ as starting metal salts during the synthetic procedure depicted in Fig. 1 (see Fig. S2 in ESI $\dagger$ for 
details). The corresponding ${ }^{15} \mathrm{~N}$ MAS-NMR spectrum in Fig. 3 shows two well-resolved ${ }^{15} \mathrm{~N}$ NMR peaks, one main peak that corresponds to triflimide anions bound to one $\mathrm{Fe}^{3+}$ atom $(-144 \mathrm{ppm})$, and a second peak upshifted $-63 \mathrm{ppm}$ that integrates for $\frac{1}{4}$ of the former. This result is in good agreement with the existence of two different triflimide anions as indicated by FT-IR and TG measurements. Moreover, the $4: 1$ ratio fits with the $\mu$-hydroxo or $\mu$-oxo bridged $\mathrm{Fe}_{2} \mathrm{O}\left(\mathrm{NTf}_{2}\right)_{5}$ species.

To obtain direct evidence for the presence of the dimeric species, an exhaustive extraction of the material was performed in different solvents, and we found that treatment of the solid in hot diethyl ether for 3 days gives a solution that contains one single compound in amounts large enough to be analysed using electrospray ionization mass spectrometry (ESI-MS). The mass obtained for this compound is 1660.9 Daltons, as shown in Fig. 3, which can be assigned to $\mathrm{Fe}_{2}\left(\mathrm{NTf}_{2}\right)_{5} \mathrm{O} \cdot\left(\mathrm{Et}_{2} \mathrm{O}\right)$ (F.W. $\left.=1601 \mathrm{D}\right)$. Matrix-assisted laserdesorption/ionization coupled to a time-of-flight mass spectrometer (MALDI-TOF-MS) confirms that no heavier species up to $40000 \mathrm{~m} / \mathrm{z}$ are present in this solution. These results indicate that the solid contains significant amounts of $\mathrm{Fe}_{2} \mathrm{O}\left(\mathrm{NTf}_{2}\right)_{5}$ species.

Electronic paramagnetic resonance (EPR) measurements of the solid showed a lack of EPR signals for Fe in the solid (Fig. S3 in ESI $\dagger$ ) which can only be explained by either very strong antiferromagnetic coupling between two $\mathrm{Fe}^{3+}$ atoms, or because the Fe centers are low spin $\mathrm{Fe}^{2+} .7$ The latter can be rejected since the material does not present any $\mathrm{Fe}^{2+}$ according to the analytical tests and RD-UV vis spectroscopy (vide supra). Thus, the fact that the material is diamagnetic at room temperature (EPR silent and no alteration in the NMR shifts) can only be explained by a strong antiferromagnetic coupling between two oxo-bridged $\mathrm{Fe}^{3+}$ atoms. Indeed, a semi-quantitative empirical correlation gives a $J=1.753 \times 10^{12} \mathrm{e}^{-12}: 663 R$, where $R$ is half of the shortest exchange pathway, equivalent to the $\mathrm{Fe}-\mathrm{O}$ distance, and agrees well with O-bridging between two $\mathrm{Fe}^{3+}$ atoms. The existence of a $\mu$-hydroxo or $\mu$-oxo bridge between two $\mathrm{Fe}^{3+}$ atoms explains the 5 triflimides in $4: 1$ ratio observed in the TG, FT-IR and ${ }^{15} \mathrm{~N}$ MAS-NMR techniques: 4 triflimides bound to a single Fe atom (two per Fe atom) and the fifth one bridging the two $\mathrm{Fe}^{3+}$ atoms, which close the hexagonal coordination sphere of each $\mathrm{Fe}^{3+}$ in the dimer $\mathrm{Fe}_{2}\left(\mathrm{NTf}_{2}\right)_{5} \mathrm{O}(\mathrm{H})$, as shown in Fig. 4 . Notice that, electronically, the $\mathrm{Fe}^{3+}$ dimer with 5 triflimides is compensated with the $\mu$-hydroxo bridge, however, a $\mu$-oxo bridge could also exist if the $\mathrm{H}^{+}$remains associated to 1,4dioxane or water molecules.

With all these data in hand, we can say that the structure of the yellow solid obtained is formed by well-dispersed $\mathrm{Ag}$ nanoparticles embedded in a matrix of $\mathrm{O}$, triflimide-dibridged

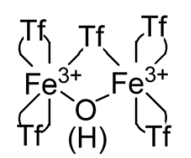

Fig. 4 Structure of the $\mathrm{Fe}^{3+}$-triflimide (Tf) dimer in the solid. Coordination of the triflimides can occur through oxygen or nitrogen atoms.
$\mathrm{Fe}^{3+}$ dimers, named hereafter as $\mathrm{Fe}_{2}\left(\mathrm{NTf}_{2}\right)_{5} \mathrm{O} @ A g N P s$ and depicted in Fig. 1. The reasonable dispersion of Ag NPs in the solid must be related to the very fast $(<1 \mathrm{~min})$ formation of the material, which prevents further agglomeration, giving finally Ag NPs without the aid of any ligand or additional support. ${ }^{8}$

\subsection{Catalytic results of $\mathrm{Fe}_{2} \mathrm{O}\left(\mathrm{NTf}_{2}\right)_{5} @ A g N P s$}

2.2.1. Acid-catalysed $\mathbf{C}-\mathbf{C}$ activation. Taking into account the potential strong acidity of the solid, its catalytic activity was tested for reactions that require an acidity value $H_{0}<-12$, i.e. reactions that can only be performed with concentrated $\mathrm{H}_{2} \mathrm{SO}_{4}$ or stronger acids. The catalytic solid material was that directly obtained from the synthetic procedure described above (i.e. precipitated, washed in hexane and dried under vacuum), and no grinding or sieving was needed to achieve reproducible results. Fig. 5 shows the results obtained for the different acidcatalysed reactions.

The head-to-tail dimerization of styrenes (Fig. 5A) is a useful reaction to obtain branched styrenes in a $100 \%$ atom-economical manner, ${ }^{9}$ and it has been catalyzed previously with, among others, Pd triflate complexes, ${ }^{\mathbf{1 0}}$ a combination of metal complexes such as $\mathrm{Pd} / \mathrm{In}$ triflate/phosphines ${ }^{\mathbf{1 1}}$ or $\mathrm{Co} / \mathrm{Zn},{ }^{12}$ and with $\mathrm{Fe}\left(\mathrm{NTf}_{2}\right)_{3},{ }^{13}$ all of them in homogenous solution. Thus, a simple solid catalyst for this reaction remains a challenge. Indeed, only the linear (not branched) dimerization of styrenes has been reported with a heterogeneous catalyst, i.e. Ru supported on $\mathrm{CeO}_{2}$, and using formaldehyde or ethanol as promoters to give a $63 \%$ yield of 1,4-diaryl-1-butenes. ${ }^{\mathbf{1 4}}$ $\mathrm{Fe}_{2}\left(\mathrm{NTf}_{2}\right)_{5} \mathrm{O} @ A g N P s$ catalyzes the regioselective head-to-tail dimerization of styrenes $1 \mathbf{1 a}-\mathbf{c}$ to $\mathbf{2 a - c}$ in yields up to $98 \%$. The hot filtration test for styrene 1a showed that the catalytic activity completely stops when the solid catalyst is filtered off, which confirms the heterogeneous nature of the catalysis.
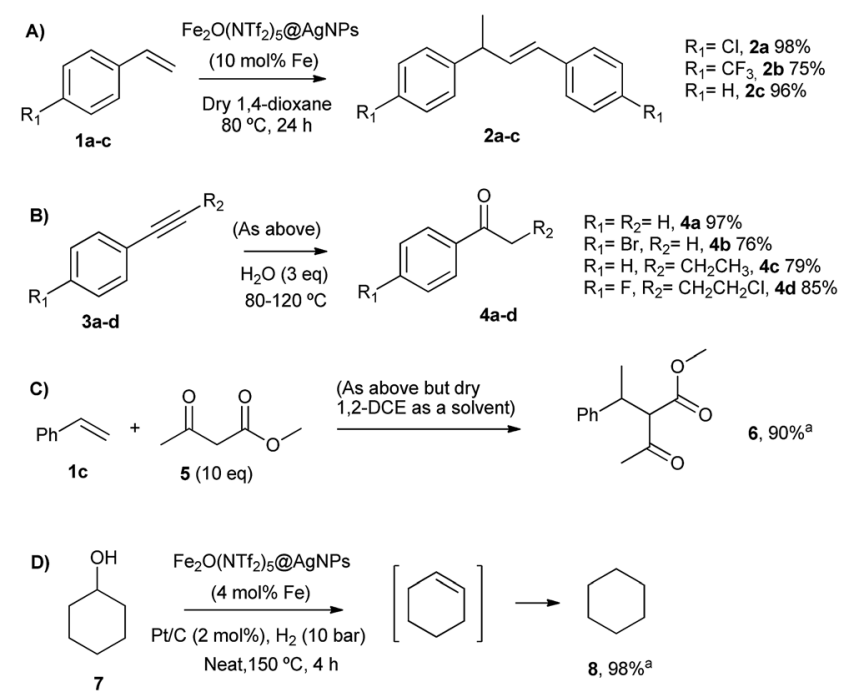

Fig. 5 Acid-catalysed reactions with $\mathrm{Fe}_{2}\left(\mathrm{NTf}_{2}\right)_{5} \mathrm{O} @ \mathrm{AgNPs}$. Isolated yields. From top to bottom: (A) head-to-tail dimerization of styrenes, (B) Markovnikov hydration of alkynes, (C) addition of methyl acetoacetate to styrene, and (D) hydrodeoxygenation of cyclohexanol. ${ }^{\mathrm{a}} \mathrm{GC}$ yield. 
The Markovnikov hydration of alkynes (Fig. 5B) was earlier catalysed by $\mathrm{Hg}$ salts at the industrial level ${ }^{15}$ and, due to toxicity issues, alternative catalysts based on transition metals are currently being explored, mainly gold. ${ }^{16-18}$ It is difficult to find efficient catalysts that operate under mild conditions beyond noble metals, ${ }^{7}$ and systems based on Brönsted acids, either homogeneous or heterogeneous, require high wt\% loadings, harsh reaction conditions $\left(>150{ }^{\circ} \mathrm{C}\right)$ or very particular modifications of the catalytic system (additives, singular reaction media such as microemulsions, and surface modifications in solids). ${ }^{19-21} \mathrm{Fe}_{2} \mathrm{O}\left(\mathrm{NTf}_{2}\right)_{5} @$ AgNPs catalyzes regioselectively the hydration of alkynes $\mathbf{3 a - d}$ to ketones $\mathbf{4 a - d}$ without any additive in up to $97 \%$ yield.

The addition of methyl acetoacetate to styrenes (Fig. 5C) was originally reported with $\mathrm{Fe}$ complexes in stoichiometric amounts $^{22}$ and further developed with noble metal catalysts, ${ }^{23}$ until Fe could be employed catalytically. ${ }^{24}$ It is not easy to find a heterogeneous catalyst for this reaction. $\mathrm{Fe}_{2} \mathrm{O}\left(\mathrm{NTf}_{2}\right)_{5} @ \mathrm{AgNPs}$ is able to catalyze the reaction between styrene 1c and methyl acetoacetate 5 to give the product $\mathbf{6}$ in $90 \%$ yield.

The hydrodeoxygenation reaction (Fig. 5D) is of interest in the biorefining industry to obtain alkanes from oxygen-rich biomass derived chemicals. ${ }^{25}$ For that, a catalytic combination of a soluble very acidic metal salt, such as a triflate, and a solid hydrogenation catalyst, such as $\mathrm{Pt} / \mathrm{C}$, is employed. ${ }^{26}$ Thus, it would be desirable to have both functions on a solid, either as a single solid or as a composite. A catalytic composite of Pt on $\mathrm{TiO}_{2} / \mathrm{C}$ has been reported ${ }^{27}$ and operates at temperatures of $\sim 300{ }^{\circ} \mathrm{C}$. Here, a composite of $\mathrm{Fe}_{2} \mathrm{O}\left(\mathrm{NTf}_{2}\right)_{5} @ A g N P s$ and $\mathrm{Pt} / \mathrm{C}$ catalyzes the hydrodeoxygenation of cyclohexanol 7 to cyclohexane 8 in $98 \%$ yield at $150{ }^{\circ} \mathrm{C}$.

In summary, $\mathrm{Fe}_{2} \mathrm{O}\left(\mathrm{NTf}_{2}\right)_{5} @ A g N P s$ catalyzes the synthetically useful, acid strength-demanding reactions shown above in very good yields, with similar catalytic activity to the state-of-the-art soluble catalysts (Table S2 $\dagger$ ). For the sake of comparison, the dimerization of styrene $\mathbf{1 a}$ and the hydration of phenylacetylene 3a were also carried out with representative strong solid acid catalysts such as Nafion ${ }^{\mathrm{TM}},{ }^{28} \mathrm{H}$-USY zeolite, ${ }^{29}$ and sulfated zirconia, ${ }^{30}$ under the indicated conditions (Fig. S4 $\dagger$ ). The results showed that only Nafion ${ }^{\mathrm{TM}}$ improves on the catalytic activity of $\mathrm{Fe}_{2}\left(\mathrm{NTf}_{2}\right)_{5} \mathrm{O}$ @AgNPs, while $\mathrm{H}$-USY and sulfated zirconia are much poorer acid catalysts, which places $\mathrm{Fe}_{2}$ $\mathrm{O}\left(\mathrm{NTf}_{2}\right)_{5} @ A g N P s$ among the most effective solid acid catalysts reported.

2.2.2. Redox-catalysed $\mathbf{C}-\mathbf{H}$ activation. Selective oxidation of $\mathrm{C}-\mathrm{H}$ bonds with environmentally benign reagents such as $\mathrm{O}_{2}$ or $\mathrm{H}_{2} \mathrm{O}_{2}$ under mild reaction conditions is one of the main challenges in organic synthesis. ${ }^{2}$ Nature makes use of enzymes with non-heme O-bridged bisiron centers, ${ }^{31}$ and successful biomimetic lines of research have been reported with O-bridged bisiron complex catalysts having low-coordinating ligands for $\mathrm{C}-\mathrm{H}$ activation and $\mathrm{C}-\mathrm{C}$ cleavage. ${ }^{32-35}$ Given the resemblance between these adducts ${ }^{32,33}$ and the $\mathrm{Fe}^{3+}$ dimer present in $\mathrm{Fe}_{2}$ $\mathrm{O}\left(\mathrm{NTf}_{2}\right)_{5} @ A g N P s$ (see Fig. 4 above), we tested $\mathrm{Fe}_{2} \mathrm{O}\left(\mathrm{NTf}_{2}\right)_{5} @$ AgNPs as a catalyst for the oxidation of alkanes under similar conditions to those reported, but without the need of adding $\mathrm{AcOH}$ to activate the iron catalyst. ${ }^{34,35}$

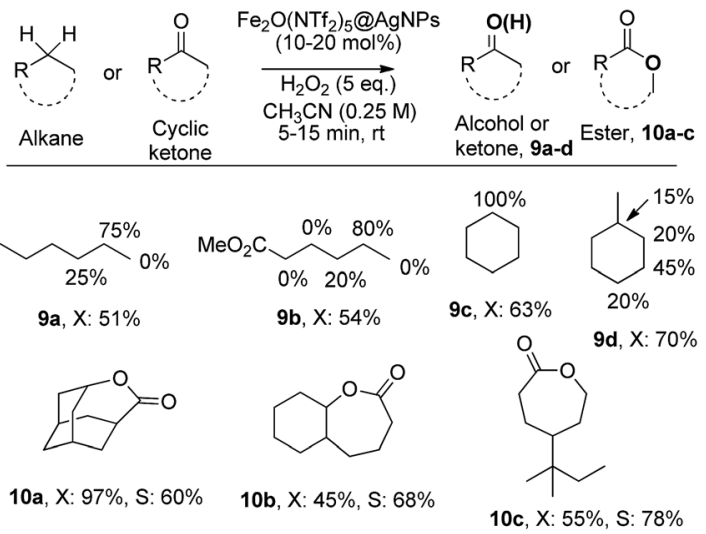

Fig. 6 Redox-catalyzed selective $\mathrm{CH}_{2}$ and Baeyer-Villiger oxidations with $\mathrm{Fe}_{2} \mathrm{O}\left(\mathrm{NTf}_{2}\right)_{5} @ A g N P s(10$ and 20 mol\% of $\mathrm{Fe}$ for alkanes and ketones, respectively). $X$ : conversion. $S$ : selectivity. GC results.

The results in Fig. 6 show that $\mathrm{Fe}_{2} \mathrm{O}\left(\mathrm{NTf}_{2}\right)_{5} @ A g N P s$ converts linear and cyclic alkanes to a mixture of alcohols and ketones $\mathbf{9 a - d}$, in reasonable conversions after a few minutes at room temperature, with good selectivity towards sterically accessible methylene groups. The solid catalyst is suitable not only for methylene oxidation but also for the Baeyer-Villiger oxidation of cyclic ketones to the corresponding cyclic esters 10a-c, ${ }^{36}$ under the same reaction conditions.

2.2.3. Acid/redox-catalysed $\mathbf{C}-\mathbf{C}$ and $\mathbf{C}-\mathbf{H}$ activation. The performance of redox catalysis in acidic media gives access to otherwise elusive reactions. Since $\mathrm{Fe}_{2} \mathrm{O}\left(\mathrm{NTf}_{2}\right)_{5}$ @AgNPs is operative in acid and redox reactions, separately, the catalytic activity of $\mathrm{Fe}_{2} \mathrm{O}\left(\mathrm{NTf}_{2}\right)_{5} @ A g N P s$ was tested for reactions that

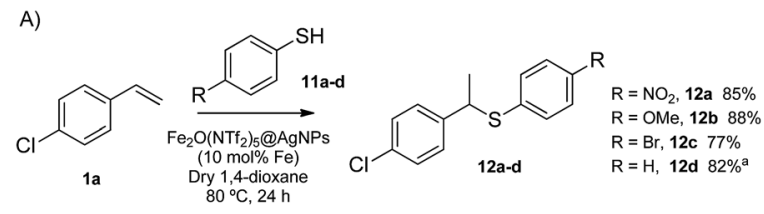

B)
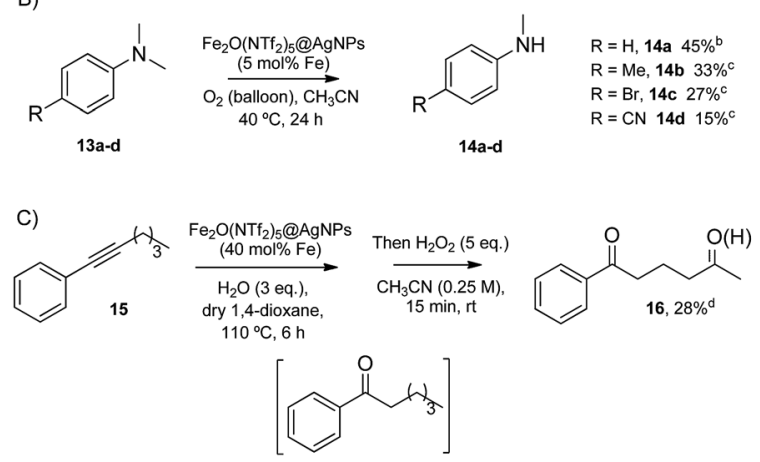

Fig. 7 Acid/redox reactions catalysed by $\mathrm{Fe}_{2}\left(\mathrm{NTf}_{2}\right)_{5} \mathrm{O} @ \mathrm{AgNPs}$. Isolated yields. From top to bottom: hydrothiolation of styrenes, demethylation of $\mathrm{N}, \mathrm{N}$-dimethylanilines, and one-pot hydration of alkyne $15-\mathrm{CH}_{2}$ oxidation. ${ }^{\mathrm{a} A f t e r} 8$ uses of $\mathrm{Fe}_{2}\left(\mathrm{NTf}_{2}\right)_{5} \mathrm{O} @ \mathrm{~A} A \mathrm{NPs}$. ${ }^{\mathrm{b}}$ Combined yield with the corresponding trimers. ${ }^{\mathrm{C}}$ Combined yield with the corresponding formamides. ${ }^{\mathrm{d}} \mathrm{GC}$ yield. 
require both functions present (see Table $\mathrm{S} 2 \uparrow$ for comparison with state-of-the-art catalysts). The results are shown in Fig. 7.

The Markovnikov hydrothiolation of styrenes is catalyzed by a $\mathrm{Fe}^{3+} / \mathrm{Fe}^{2+}$ manifold mechanism with the participation of protons in the redox catalytic cycle. ${ }^{37}$ The results obtained (Fig. 7A) show that $\mathrm{Fe}_{2} \mathrm{O}\left(\mathrm{NTf}_{2}\right)_{5} @ A g N P s$ is as active as the stateof-the-art soluble catalysts, ${ }^{38}$ with good yields for the representative products $\mathbf{1 2 a}-\mathbf{d}$. Besides, the solid catalyst could be reused up to 9 times after simple filtration, without a significant loss of its inherent catalytic activity (Fig. S5†).

The selective demethylation of $N, N$-dimethylanilines is a biomimetic reaction catalyzed by iron complexes in the presence of strong oxidants, such as PhIO. ${ }^{39}$ Nature makes use of $\mathrm{O}_{2}$ as the terminal oxidant, thus the synthetic use of $\mathrm{O}_{2}$ as an environmentally-friendly oxidant for this reaction would be a significant advance. Recently, it has been reported that this reaction can moderately occur under aerobic conditions $(\sim 40 \%$ combined yield with trimers and formamides) if a metal triflate salt, i.e. $\mathrm{Zn}^{2+}, \mathrm{Ba}^{2+}$ or $\mathrm{Y}^{3+}$, is used in combination with the $\mathrm{Fe}^{3+}$ complex to form a triflate bridge between the two metal cations. ${ }^{40}$ It was envisioned that the solid triflimide composed of Fe dimers could mimic this system and catalyze the demethylation of $\mathrm{N}, \mathrm{N}$-dimethylanilines under similar aerobic conditions (Fig. 7B). Indeed, the reaction worked well with $\mathrm{Fe}_{2} \mathrm{O}\left(\mathrm{NTf}_{2}\right)_{5} @ A g N P s$, with similar yields and better selectivity for the products than with the soluble metal complex since, presumably, the higher acidity of the triflimide solid overrides undesired biphenyl formation by the non-acidic aryl/Fe electron transfer. $^{\mathbf{4 0}}$

The possibility of engaging the hydration of the aryl alkyl alkyne $\mathbf{1 5}$ and the methylene oxidation reaction in cascade ${ }^{\mathbf{4 1}}$ was also tested, with $\mathrm{Fe}_{2} \mathrm{O}\left(\mathrm{NTf}_{2}\right)_{5} @ A g N P s$ as a single catalyst for both processes (Fig. 7C). The result shows that the solid triflimide indeed preserves its redox catalytic activity after acting as an acid catalyst, and the 1,5-diketone $\mathbf{1 6}$ is thus formed in one-pot. Notice that the regioselective formation of the first carbonyl group by acid-catalyzed hydration directs the later oxidation of the methylene group.

2.2.4. Making the Ag NPs accessible to reactants. When the solid with an $\mathrm{Ag}: \mathrm{Fe}$ ratio $=0.5$ was tested for reactions typically catalyzed by Ag NPs of $\sim 10 \mathrm{~nm}$, including the epoxidation of styrene, ${ }^{42}$ the aerobic dehydrogenation of alcohols ${ }^{43}$ and the synthesis of azocompounds from anilines (see Fig. S6 in ESI $\dagger$ ), ${ }^{44}$ no conversion was found for any of these reactions. Blank experiments with independently synthesized Ag NPs of $\sim 10 \mathrm{~nm}$ showed the expected reactivity for the Ag catalyst. ${ }^{\mathbf{4 2 - 4 4}}$ Therefore, the lack of catalytic activity of the $\mathrm{Ag}$ nanoparticles in the $\mathrm{Fe}_{2}$ $\mathrm{O}\left(\mathrm{NTf}_{2}\right)_{5} @ A g N P s$ solid suggests that the contact between Ag NPs and the reactants may be hampered in some way. To further assess if the Ag NPs in the solid were accessible to the reactant molecules, in situ low-temperature FT-IR experiments with carbon monoxide (CO), as a probe molecule, were carried out (Fig. S7 in ESI $\dagger$ ). The results show that there is no interaction between $\mathrm{CO}$ and $\mathrm{Ag}^{0}$ or $\mathrm{Ag}^{\delta+}$ atoms, ${ }^{45}$ which unequivocally indicates that the $\mathrm{Ag}$ atoms in the solid are not accessible to external chemicals. The lack of interaction between $\mathrm{CO}$ and $\mathrm{Fe}^{3+}$ was expected due to the low-coordinating nature of the triflimide anions and reflects the high acidity of the $\mathrm{Fe}^{3+}$ atoms in the solid. Considering the amount and size of Ag NPs in the material for $\mathrm{Ag}: \mathrm{Fe}$ ratios $\leq 0.5$ and the number of $\mathrm{Fe}$ atoms, a simple calculation shows that the number of Fe dimers is at least $10^{4}$ higher than the number of $\mathrm{Ag}$ nanoparticles. Thus, there are enough $\mathrm{Fe}_{2} \mathrm{O}\left(\mathrm{NTf}_{2}\right)_{5}$ molecules to embed all the NPs. In fact, only $5 \%$ of $\mathrm{Fe}$ dimers are enough to cover the whole surface of the $\mathrm{Ag}$ NPs. It appears then that the $\mathrm{Fe}^{3+}$ matrix acts as a chemical shield for the Ag NPs, conferring them protection against air, water or any other external atmosphere. For instance, the material $(\mathrm{Ag}: \mathrm{Fe}$ mol ratio $=0.5)$ is stable after heating at $200{ }^{\circ} \mathrm{C}$ for 1 day under an $\mathrm{H}_{2}$ atmosphere of 10 bars and no agglomeration of $\mathrm{Ag}$ NPs was observed after this treatment.

However, it should be in principle possible to make accessible the Ag NPs in the solid by just increasing the Ag to $\mathrm{Fe}^{3+}$ ratio, in such a way that the $\mathrm{Fe}^{3+}$ triflimide dimers will not completely cover the Ag NPs. Fig. 8 shows that, indeed, the solid material has clearly visible $\sim 10 \mathrm{~nm} \mathrm{Ag}$ NPs on the surface when the synthesis is performed with an $\mathrm{Ag}: \mathrm{Fe}$ mol ratio $=1$. The resultant material with accessible Ag NPs is active for the classical Ag-catalyzed reaction of aniline to give azobenzene. ${ }^{44}$ The solid catalyst now gives a $20 \%$ conversion with a turnover number (TOF) relative to the exposed Ag atoms of 100 (see Fig. S6 in ESI $\dagger$ ). Comparatively, the $\mathrm{Ag}:$ Fe mol ratio $=0.5$ solid is completely inactive and commercially available $\mathrm{Ag} / \mathrm{C}$ gives only $7 \%$ conversion. These results confirm that the accessibility of the reactants to the Ag NPs in the solid material can be regulated by varying the relative amount of metals during the synthesis.

In summary, the results shown in Section 2.2 provide a picture of the rather unique acid/redox catalytic behavior of the $\mathrm{Fe}_{2} \mathrm{O}\left(\mathrm{NTf}_{2}\right)_{5} @ A g N P s$ solid.

\subsection{Mechanism of formation of $\mathrm{Fe}_{2} \mathrm{O}\left(\mathrm{NTf}_{2}\right)_{5} @ \mathrm{AgNPs}$}

A possible mechanism for the formation of the $\mathrm{Fe}_{2} \mathrm{O}\left(\mathrm{NTf}_{2}\right)_{5}$ @ AgNPs solid is depicted in Fig. 9. This mechanism is supported by reactivity tests and isotopic experiments, and it consists of the one-electron reduction of $\mathrm{Fe}\left(\mathrm{NTf}_{2}\right)_{3}$ to $\mathrm{Fe}\left(\mathrm{NTf}_{2}\right)_{2}$ by $\mathrm{PhSH}$, forming a coordinatively unsaturated $\mathrm{Fe}^{2+}$ species that re-

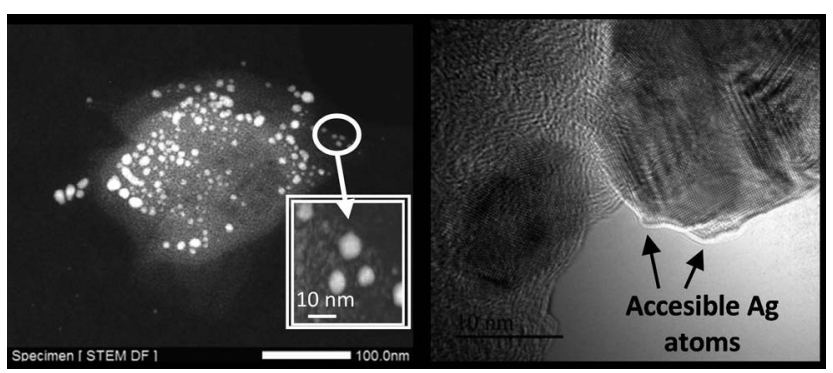

Fig. 8 Scanning transmission electron microscopy-dark field (STEMDF, left) and high-resolution transmission electron microscopy (HRTEM, right, black bar accounts for $10 \mathrm{~nm}$ ) photographs of $\mathrm{Fe}_{2}-$ $\mathrm{O}\left(\mathrm{NTf}_{2}\right)_{5} @ \mathrm{AgNPs}$ synthesized with a $\mathrm{Ag}: \mathrm{Fe}^{3+} \mathrm{mol}$ ratio $=1$. The inset magnifies a particular area (inverted). 


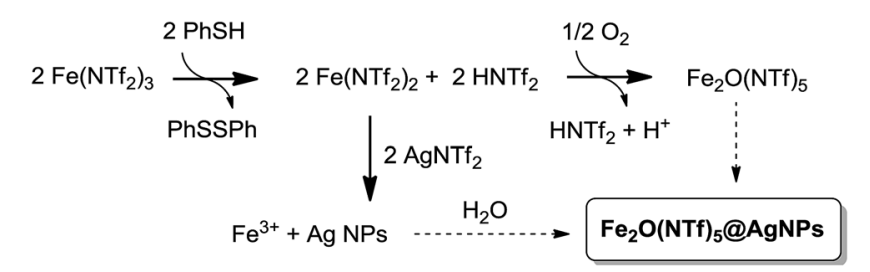

Fig. 9 Proposed mechanism for the formation of $\mathrm{Fe}_{2} \mathrm{O}\left(\mathrm{NTf}_{2}\right)_{5} @ \mathrm{AgNPs}$.

oxidizes at expense of reducing $\mathrm{Ag}^{+}$to $\mathrm{Ag}$ NPs or, alternatively, with air.

The one-electron reduction of $\mathrm{Fe}\left(\mathrm{NTf}_{2}\right)_{3}$ to $\mathrm{Fe}\left(\mathrm{NTf}_{2}\right)$ is supported by the quantitative transformation of the one-electron reductant $\mathrm{PhSH}$ to diphenyl disulfide $\mathrm{Ph}_{2} \mathrm{~S}_{2}$, observed using GCMS and liquid NMR measurements of the solution, when $\mathrm{PhSH}$ is added to a mixture of $\mathrm{Fe}\left(\mathrm{NTf}_{2}\right)_{3}$ and $\mathrm{AgNTf}_{2}$, to form the yellow solid. In contrast, if $\mathrm{PhSH}$ is added to a solution of $\mathrm{Fe}\left(\mathrm{NTf}_{2}\right)_{3}$ without AgNTf 2 present in the medium, the solid does not form despite $\mathrm{Ph}_{2} \mathrm{~S}_{2}$ being quantitatively produced. Furthermore, if $\mathrm{PhSH}$ is added to a solution of $\mathrm{AgNTf}_{2}$ without $\mathrm{Fe}\left(\mathrm{NTf}_{2}\right)_{3}$ present, no reaction occurs. These results indicate that the one-electron reduction occurs to form $\mathrm{Fe}^{2+}$, in agreement with the well-known single electron transfer (SET) process between $\mathrm{PhSH}$ and $\mathrm{Fe}^{3+}$ salts at room temperature. ${ }^{37}$ Other potential reductants for $\mathrm{Fe}^{3+}$ such as isopropanol and $\mathrm{Ce}^{3+}$ failed to form the solid.

The yield of solid decreases significantly if an excess of $\mathrm{PhSH}$ with respect to metal triflimide is employed during the synthesis $(90 \%, 65 \%$, and $28 \%$ for 1,3 and 10 equivalents of $\mathrm{PhSH}$, respectively), due to the formation of stable $\mathrm{Ag}^{+}$-thiolate complexes. When Au, Pd and Pt salts were tested instead of Ag no solid formation occurred. These results, in principle, discard the possibility that thiophenol acts as a "seed" for nanoparticle formation, and the SET transfer reaction seems to be predominant in the mechanism.

The second step in the mechanism of formation of the bimetallic solid is a redox reaction between the in situ formed $\mathrm{Fe}^{2+}$ and $\mathrm{Ag}^{+}$, to give $\mathrm{Fe}^{3+}$ and $\mathrm{Ag}$ NPs, as expected from their respective redox potentials. Accordingly, the $\mathrm{pH}$ of the solution is made very acidic $(<1)$ by the released triflimidic acid, and the protons may stay either coordinated to the oxygen atoms of the O-bridges or to the dioxane molecules.

The third and last step is the formation of the $\mu$-oxo or $\mu$-hydroxo bridge between two $\mathrm{Fe}^{3+}$ atoms. To shed light on this step, we used an atmosphere of ${ }^{18} \mathrm{O}_{2}$, and the corresponding FTIR spectrum of the yellow solid showed the formation of an Fe- ${ }^{18} \mathrm{O}-\mathrm{Fe}$ bridge according to the slight shift of the corresponding IR band with respect to the non-labelled yellow solid (see Fig. 3). ${ }^{6}$ Additionally, we found that $\mathrm{H}_{2}{ }^{18} \mathrm{O}$ is formed in solution, as determined by CG-MS. These results support that $\mathrm{Fe}^{2+}$ oxidizes to $\mathrm{Fe}^{3+}$ not only with $\mathrm{Ag}^{+}$but also with the $\mathrm{O}_{2}$ present in the atmosphere, and that $\mathrm{O}_{2}$ is then reduced to $\mathrm{H}_{2} \mathrm{O}$. This reaction complements the oxidation with $\mathrm{Ag}^{+}$and closes the mass balance. The bridged oxygen atom would then come from reduced molecular oxygen, either directly or after reduction to $\mathrm{H}_{2} \mathrm{O}$. To test this last possibility, $\mathrm{H}_{2}{ }^{18} \mathrm{O}$ was added to an anhydrous solution of triflimides prior to the formation of the solid under air. As occurred previously when working with an ${ }^{18} \mathrm{O}_{2}$ atmosphere, the formation of the isotopically-labelled $\mathrm{Fe}_{2}{ }^{18} \mathrm{O}\left(\mathrm{NTf}_{2}\right)_{5} @$ AgNPs was observed, with the concomitant consumption of $\mathrm{H}_{2}{ }^{18} \mathrm{O}$ observed using GC-MS. These results support that the oxygen atom for the O-bridged $\mathrm{Fe}^{3+}$ dimer comes from water molecules present in the medium. If so, the bridge should also be produced under an inert atmosphere provided that water is in the medium. Indeed, a $65 \%$ yield of solid was obtained under $\mathrm{N}_{2}$ when 0.5 equivalents of $\mathrm{Ag}$ were used. It must be noticed, however, that the formation of the bridge is less efficient in the absence of $\mathrm{O}_{2}$ since a $90 \%$ yield is obtained when the process is run aerobically, which is explained by the better oxidation of $\mathrm{Fe}^{2+}$ to $\mathrm{Fe}^{3+}$ when molecular oxygen is present.

All the steps described above occur in less than 1 minute at room temperature, and the formation of a coordinatively unsaturated $\mathrm{Fe}\left(\mathrm{NTf}_{2}\right)_{2}$ species seems to play a key role in the formation of the solid, accommodating the bridging $\mathrm{NTf}_{2}$ and $\mathrm{O}$ species. In agreement with this, when a sample of independently prepared $\mathrm{Fe}^{2+}\left(\mathrm{NTf}_{2}\right)_{2}$ was used as the starting material to form the solid, ${ }^{13}$ with the whole hexacoordination sphere saturated ( 2 bridging triflimides and 4 bisoxo-coordinated terminal triflimides, 2 per $\mathrm{Fe}^{2+}$ atom), no solid was formed. This result evidences the need for in situ reducing the $\mathrm{Fe}^{3+}$ triflimide.

\subsection{Extension of the work to other metallic systems: synthesis of $\mathrm{Cu}, \mathrm{Bi}$ and Yb-triflimide@AgNPs}

According to the mechanism in Fig. 9, it might be expected that other metal cations could participate in the proposed redox sequence, as long as the corresponding metal triflimide can suffer the SET reduction with $\mathrm{PhSH}$ and the generated reduced metal cation is re-oxidized back with $\mathrm{O}_{2}$ and/or $\mathrm{Ag}^{+}$. If so, a family of ligand-free, self-supported bimetallic solids could be available following the preparation method described here. After examining the redox potentials of tabulated metal cations and testing those suitable, we found that the triflimides of $\mathrm{Cu}^{2+}, \mathrm{Yb}^{3+}$ and $\mathrm{Bi}^{3+}$ were able to form the corresponding solids in moderate to good yields ( $84 \%$ for copper, $75 \%$ for bismuth and $63 \%$ for ytterbium) under the same reaction conditions as for $\mathrm{Fe}_{2} \mathrm{O}\left(\mathrm{NTf}_{2}\right)_{5}$ @ AgNPs. Other cations such as $\mathrm{Ru}^{3+}$ or $\mathrm{Co}^{3+}$ failed to produce the corresponding solids.

Fig. 10 shows the characterization of the solids using FT-IR and TEM. The results suggest that, in principle, these solids have a similar structure to $\mathrm{Fe}_{2} \mathrm{O}\left(\mathrm{NTf}_{2}\right)_{5}$ @AgNPs, i.e. they are formed by well-dispersed Ag NPs embedded within a metal triflimide matrix. In the case of $\mathrm{Cu}$, the $\mathrm{Ag}$ NPs flourish to the surface (see left microphotograph in Fig. 10).

The $\mathrm{Cu}$ and $\mathrm{Bi}$ materials were tested as catalysts in the vinylation of 1,3-diphenylpropargyl alcohol ${ }^{46-48}$ and in the hydrothiolation of styrenes, ${ }^{37}$ respectively. Fig. 11 shows that products 18 and 12d were obtained in good yields, similar to those previously reported. 

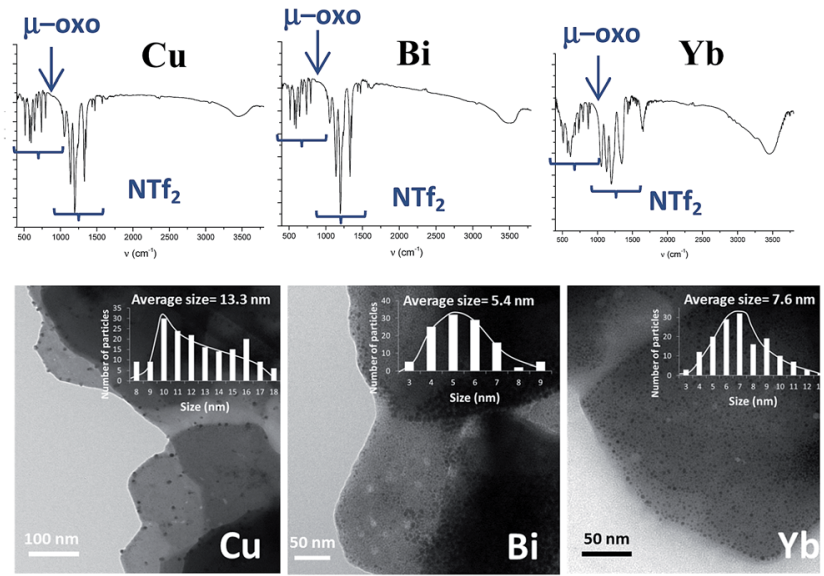

Fig. 10 Top: FT-IR spectra of the solids made by the same procedure as $\mathrm{Fe}_{2} \mathrm{O}\left(\mathrm{NTf}_{2}\right)_{5} @ \mathrm{AgNPs}$ but with $\mathrm{Cu}\left(\mathrm{NTf}_{2}\right)_{2}, \mathrm{Bi}\left(\mathrm{NTf}_{2}\right)_{3}$ and $\mathrm{Yb}\left(\mathrm{NTf}_{2}\right)_{3}$ as starting materials, from left to right, respectively. Bottom: transmission electron microscopy (TEM) photographs with the corresponding histograms for, at least, 5 different photos.
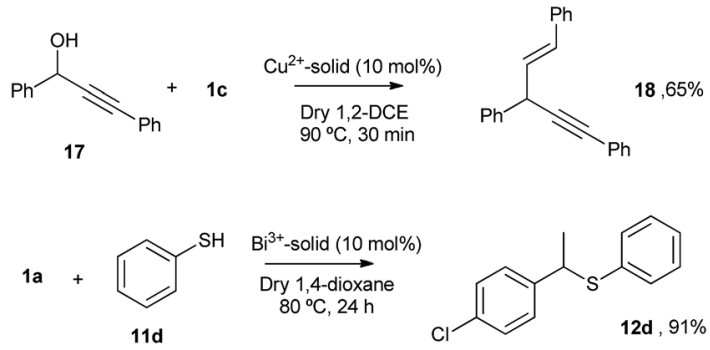

Fig. 11 Top: vinylation of 1,3-diphenylpropargyl alcohol 17 with styrene 1c catalyzed by the Cu-triflimideaAgNPs solid. Bottom: hydrothiolation of 4-chlorostyrene $1 \mathrm{a}$ catalyzed by the Bi-triflimide@AgNPs solid. GC yields.

\section{Conclusions}

The direct synthesis of self-supported triflimide metal matrices on $\mathrm{Ag}$ nanoparticles has been accomplished by a conceptuallynew procedure that involves a redox-coupled sequence of two metal salts under air. ${ }^{\mathbf{4 9 , 5 0}}$ This straightforward, sustainable and high-scale method of preparation of a catalytic triflimide solid opens a new way of synthesizing strong solid acids with redox sites. The nanosized bimetallic solids here formed can act as an acid catalyst, a redox catalyst or a bifunctional acid/redox catalyst.

\section{Acknowledgements}

Financial support by the "Severo Ochoa" program, RETOS program (CTQ2014-55178 R) and Ramón y Cajal Program (A. L.P.) by MINECO (Spain), and also by "Convocatoria 2014 de Ayudas Fundación BBVA a Investigadores y Creadores Culturales" are acknowledged. The Electron Microscopy Service of the UPV is also acknowledged.

\section{Notes and references}

1 S. Antoniotti, V. Dalla and E. Duñach, Angew. Chem., Int. Ed., 2010, 49, 7860.

2 M. C. White, Science, 2012, 335, 807.

3 F.-X. Felpin and E. Fouquet, ChemSusChem, 2008, 1, 718.

4 U. Diaz, D. Brunel and A. Corma, Chem. Soc. Rev., 2013, 42, 4083.

5 I. Rey, P. Johansson, J. Lindgren, J. C. Lassègues, J. Grondin and L. Servant, J. Phys. Chem. A, 1998, 102, 3249.

6 D. M. J. Kurtz, Chem. Rev., 1990, 90, 585.

7 J. R. Cabrero-Antonino, A. Leyva-Pérez and A. Corma, Chem.Eur. J., 2012, 18, 11107.

8 A. Desireddy, B. E. Conn, J. Guo, B. Yoon, R. N. Barnett, B. M. Monahan, K. Kirschbaum, W. P. Griffith, R. L. Whetten, U. Landman and T. P. Bigioni, Nature, 2013, 501, 399.

9 J. Skupiçska, Chem. Rev., 1991, 91, 613.

10 J. H. Choi, J. K. Kwon, T. V. RajanBabu and H. J. Lim, Adv. Synth. Catal., 2013, 355, 3633.

11 R. B. Bedford, M. E. Betham, M. Blake, A. S. Garcés, S. L. Millar and S. Prashar, Tetrahedron, 2005, 61, 9799.

12 C.-C. Wang, P.-S. Lin and C.-H. Cheng, Tetrahedron Lett., 2004, 45, 6203.

13 J. R. Cabrero-Antonino, A. Leyva-Pérez and A. Corma, Adv. Synth. Catal., 2010, 352, 1571.

14 S. Shimura, H. Miura, S. Tsukada, K. Wada, S. Hosokawa and M. Inoue, ChemCatChem, 2012, 4, 2062.

15 L. Hintermann and A. Labonne, Synthesis, 2007, 1121.

16 R. E. Ebule, D. Malhotra, G. B. Hammond and B. Xu, Adv. Synth. Catal., 2016, 358, 1478.

17 S. Liang, J. Jasinski, G. B. Hammond and B. Xu, Org. Lett., 2015, 17, 162.

18 A. Leyva and A. Corma, J. Org. Chem., 2009, 74, 2067.

19 Z. Nairoukh, D. Avnir and J. Blum, ChemSusChem, 2013, 6, 430.

20 N. Mameda, S. Peraka, M. R. Marri, S. Kodumuri, D. Chevella, N. Gutta and N. Nama, Appl. Catal., A, 2015, 505, 213.

21 F. Alonso, I. P. Beletskaya and M. Yus, Chem. Rev., 2004, 104, 3079.

22 P. Lennon, A. M. Rosan and M. Rosenblum, J. Am. Chem. Soc., 1977, 99, 8426.

23 H. Qian and R. A. Widenhoefer, J. Am. Chem. Soc., 2003, 125, 2056.

24 J. Kischel, D. Michalik, A. Zapf and M. Beller, Chem.-Asian J., 2007, 2, 909.

25 G. W. Huber, S. Iborra and A. Corma, Chem. Rev., 2006, 106, 4044.

26 Z. Li, R. S. Assary, A. C. Atesin, L. A. Curtiss and T. J. Marks, J. Am. Chem. Soc., 2014, 136, 104.

27 A. Corma, O. de la Torre, M. Rentz and N. Villandier, Angew. Chem., Int. Ed., 2011, 50, 2375.

28 G. Gelbard, Ind. Eng. Chem. Res., 2005, 44, 8468.

29 J. R. Cabrero-Antonino, A. Leyva-Pérez and A. Corma, Angew. Chem., Int. Ed., 2015, 54, 5658. 
30 K. Arata, Green Chem., 2009, 11, 1719.

31 C. E. Tinberg and S. J. Lippard, Acc. Chem. Res., 2011, 44, 280.

32 R. A. Leising, J. Kim, M. A. Pérez and L. Que Jr, J. Am. Chem. Soc., 1993, 115, 9524.

33 N. Raffard-Pons, Y. Moll, F. Banse, K. Miki, M. Nierlich and J.-J. Girerd, Eur. J. Inorg. Chem., 2002, 1941.

34 M. S. Chen and M. C. White, Science, 2010, 327, 566.

35 P. E. Gormisky and M. C. White, J. Am. Chem. Soc., 2013, 135, 14052.

36 A. Corma, L. T. Nemeth, M. Renz and S. Valencia, Nature, 2001, 412, 423.

37 J. R. Cabrero-Antonino, A. Leyva-Pérez and A. Corma, Adv. Synth. Catal., 2012, 354, 678.

38 R. Castarlenas, A. Di Giuseppe, J. J. Pérez-Torrente and L. A. Oro, Angew. Chem., Int. Ed., 2013, 52, 211.

39 E. Baciocchi, O. Lanzalunga, A. Lapi and L. Manduchi, J. Am. Chem. Soc., 1998, 120, 5783.

40 J. Zhang, Y. Wang, N. Luo, Z. Chen, K. Wu and G. Yin, Dalton Trans., 2015, 44, 9847.
41 A. Leyva-Pérez, P. García-García and A. Corma, Angew. Chem., Int. Ed., 2014, 53, 8687.

42 R. Xu, D. Wang, J. Zhang and Y. Li, Chem.-Asian J., 2006, 1, 888.

43 T. Mitsudome, Y. Mikami, H. Funai, T. Mizugaki, K. Jitsukawa and K. Kaneda, Angew. Chem., Int. Ed., 2008, 47, 138.

44 S. Cai, H. Rong, X. Yu, X. Liu, D. Wang, W. He and Y. Li, ACS Catal., 2013, 3, 478.

45 Z. Qu, S. Zhou, W. Wu, C. Li and X. Bao, Catal. Lett., 2005, 101, 21.

46 G.-B. Huang, X. Wang, Y.-M. Pan, H.-S. Wang, G.-Y. Yao and Y. Zhang, J. Org. Chem., 2013, 78, 2742.

47 J. Kischel, K. Mertins, D. Michalik, A. Zapf and M. Beller, Adv. Synth. Catal., 2007, 349, 865.

48 P. Moriel and A. B. García, Green Chem., 2014, 16, 4306.

49 Z. Wang, G. Chen and K. Ding, Chem. Rev., 2009, 109, 322.

50 H. Chen, D. Wang, Y. Yu, K. A. Newton, D. A. Muller, H. D. Abruña and F. J. DiSalvo, J. Am. Chem. Soc., 2012, 134, 18453. 